\title{
EFFECT OF ORCHARD PESTICIDES ON APHELINUS MALI, THE WOOLLY APPLE APHID PARASITOID
}

\author{
S.J. BRADLEY, V.C. MURRELL, P.W. SHAW ${ }^{1}$ and J.T.S. WALKER
}

\author{
The Horticultural and Food Research Institute of New Zealand Ltd \\ Hawkes Bay Research Centre, Private Bag 1401, Havelock North, \\ ${ }^{1}$ Nelson Research Centre, P.O. Box 220, Motueka
}

\begin{abstract}
A laboratory bioassay and field trials were used to evaluate the effect of 31 pesticides on Aphelinus mali, a parasitoid of woolly apple aphid. Adults were caged for 16 hours in Petri dishes containing treated filter paper. Carbaryl, chlorpyrifos, diazinon and pyrethrum were highly toxic, while azinphos-methyl and omethoate showed low to moderate toxicity. In a field study, orchard blocks were treated with chlorpyrifos plus oil, buprofezin plus oil, oil, diazinon, carbaryl and pirimicarb. The number of adult $A$. mali caught in white sticky traps was reduced in the chlorpyrifos and carbaryl treatments. The implications for woolly apple aphid control in an Integrated Fruit Production programme are discussed.
\end{abstract}

Keywords: Aphelinus mali, woolly apple aphid, Eriosoma lanigerum, pesticides, beneficials

\section{INTRODUCTION}

Aphelinusmali(Haldeman)(Hymenoptera: Aphelinidae) is a specific endoparasitoid of woolly apple aphid (WAA), Eriosoma lanigerum (Hausemann)(Homoptera: Pemphigidae). In the absence of disruptive pesticides, A. mali is an important factor regulating WAA populations (Shaw and Walker 1996). The widespread use of broad-spectrum organophosphate insecticides for insect control in New Zealand apple orchards results in low populations of WAA and A. mali is rarely observed. Integrated fruit production (IFP) is a systems-based approach to fruit production in which pest control is principally based on biological control, backed up with selective insecticide applications when established thresholds have been exceeded (Batcheloret al. 1997). The adoption of IFP on New Zealand apple orchards is well underway (Walker et al. 1997) and orchards in the transitional phase of IFP are likely to face resurgence of WAA, previously suppressed through the use of broad-spectrum insecticides (e.g. Shaw and Walker 1996). IFP allows insecticides to be applied to WAA populations that are at, or will reach, damaging or contaminating levels. Unfortunately, these treatments also affect $A$. mali and can destabilise natural biological control.

Ideally, selective chemicals should be chosen to minimise any disruption to A. mali, but there are little published data on the effect of chemicals onA. mali. This paper reports the results of a bioassay which examined the effect of chemical residues on adult A. mali and the presence of A. mali adults in field plots following various treatments.

\section{Adult bioassay}

\section{METHODS}

Using aspirators, 20-40 adult $A$. mali were collected into small vials from apple tree trunks and wind-fallen apples. Insects were refrigerated and used within five hours. Stock solutions of the chemicals listed in Table 1 were mixed using a magnetic stirrer and stored in a refrigerator for up to 10 days. Solutions were diluted to half or quarter field rate on the day of the bioassay.

The bioassay consisted of an $87 \mathrm{~mm}$ disc of Whatman \#1 grade filter paper placed into the lid of a $90 \mathrm{~mm}$ Petri dish. Using a pipette, $0.5 \mathrm{ml}$ of a solution was dropped evenly over the surface of the paper and left to evaporate until dry (15-20 min). Either four or 
eight replicates were tested per product and concentration. The A. mali adults were transferred into the dish, the base was replaced and sealed with clingfilm. The number of insects that had died during handling was recorded immediately and subtracted from bioassay results, while the remainder were held at $20^{\circ} \mathrm{C}$ for $16 \mathrm{hr}$ and examined to determine treatment mortalities. Adults were classified as dead when they were no longer standing. Results were corrected for mortality in the water controls using Abbott's correction (Abbott 1925).

\section{Field Study}

The field study was carried out on HortResearch properties in Nelson and Hawkes Bay. On 8 September 1996, a 0.25 ha 'Sturmer' and a 0.25 ha 'Granny Smith' block in Nelson, received a 'green-tip' (stage of bud-burst) application of buprofezin plus oil, while adjacent blocks of similar size received an application of chlorpyrifos plus oil. The respective Sturmer plots received a second buprofezin on 27 September or second chlorpyrifos on 26 November. Adult A. mali numbers were counted from weekly inspections of sticky San José scale (Quadraspidiotus perniciosus (Comstock)) pheromone traps $(13 \times 8 \mathrm{~cm}$, Trécé, Salinas CA.). Ten shoots on 20 trees per plot were monitored for presence/absence of WAA colonies at regular intervals throughout the season.

In Hawkes Bay, two 'Gala' blocks and a 'Braeburn' block were divided into three 0.13 ha plots, receiving either chlorpyrifos and oil, buprofezin and oil, or oil alone on 2 September 1996. An adjacent 'Fuji' block received oil alone on 2 September and was then divided into three plots receiving either carbaryl, diazinon or no spray on 11 November 1996. Two of the treated Fuji plots (carbaryl, diazinon), later received a pirimicarb on 31 January 1997. All applications were made using an air-blast sprayer at rates listed in Table 2. In Hawkes Bay, a 18 x $19 \mathrm{~cm}$ white sticky board (HortResearch, Auckland) was hung vertically in the centre of each plot on 22 October, checked weekly for A. mali adults and replaced every three weeks.

In the 'green-tip' treatments, which used the two Nelson cultivar and three Hawkes Bay cultivar blocks as replicates, the number of adult $A$. mali caught between 21 October and 25 November 1996 (the main period of spring activity) was log transformed and analysed using ANOVA and means separated using Fisher's LSD. Applications of pesticides in the Fuji plots were unreplicated, so trap catch in the treated plots was divided by trap catch from both treated and untreated plots to give a ratio. The ratios from treated plots before and after treatment were compared using $\mathrm{T}$-tests to determine whether any relative change in $A$. mali activity had occurred. This method was a modified version of McDonald and Erickson (1994) test for bioequivalence.

\section{Adult bioassay}

\section{RESULTS AND DISCUSSION}

The mean adult mortality in the water controls was $7 \%$ and corrected adult mortalities for the pesticides tested are presented in Table 1. Earlier bioassays were affected by higher than expected mortalities in some dishes. This problem was remedied by replacement of aspiration equipment. These unexpected results are apparent in the large confidence intervals for some products, and inconsistent rate responses, despite the addition of extra replicates.

Carbaryl, chlorpyrifos, diazinon and pyrethrum residues where found to be highly toxic to $A$. mali adults. Imidacloprid and omethoate showed moderate to high toxicity, while azinphos-methyl and taufluvalinate showed low toxicity in this bioassay. All other compounds tested using this bioassay, including many organophosphates, showed no detrimental effects to adult $A$. mali. No miticide or fungicide treatments showed any detrimental effect. Schneider (1958) also found most fungicides, except wettable sulphur, to be benign to $A$. mali.

TABLE 1: The corrected mortality ( $₫ 95 \%$ confidence interval) of Aphelinus mali adults exposed to pesticide residues. Treatment means from either four or eight $(*)$ replicates. 


\begin{tabular}{lcccc} 
& $\begin{array}{c}\text { Field } \\
\text { rate }\end{array}$ & \multicolumn{2}{c}{$\begin{array}{c}\text { Percentcorrected } \\
\text { mortality at rate }\end{array}$} & \\
\cline { 3 - 4 } Activeingredient & Formulation & $\begin{array}{c}\text { product } \\
/ 100 \text { litres }\end{array}$ & field & half quarter Toxicity $^{1}$ \\
\hline
\end{tabular}

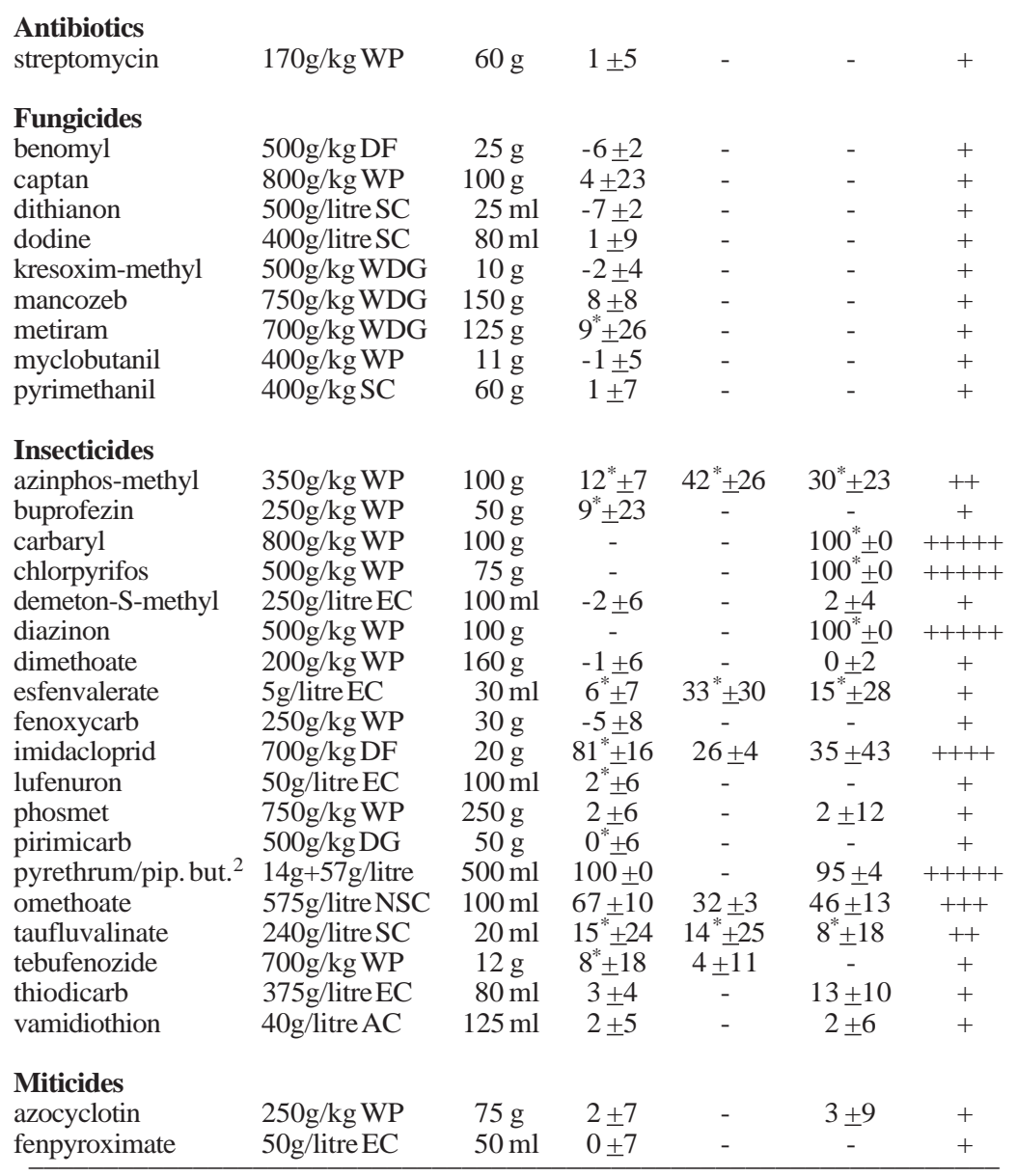

${ }^{1}$ Toxicity rating from Croft $(1982) ;+(<10 \%)$ no or little toxicity; $++(10-40 \%)$ low toxicity; +++ (50-70\%) moderate toxicity; ++++ (75-90\%) high toxicity; +++++ $(99.99 \%)$ kill

${ }^{2}$ Piperonyl butoxide.

This bioassay may overestimate the potential impact of some pesticides with a short residual life. In the field, the multiple life stages of $A$. mali, variability in spray coverage, possible repellency effects and short residual activity may exhibit different responses than seen with treated filter papers in enclosed Petri dishes. The bioassay does not address any of the potential effects on the developing parasitoid within the aphid (which is the likely period of action for many of the new insect growth regulators), or any potential effect on behaviour. The bioassay also does not take into account any effect, or lack of 
effect on WAA. Chemicals which have no effect on WAA, but have a low to moderate effect on A. mali can disrupt biological WAA control. This can only be assessed in field trials over longer assessment periods, with plots of sufficient size to negate immigration effects on WAA populations.

TABLE 2: The number of adult Aphelinus mali caught in white sticky traps, before and after air-blast applications of orchard chemicals and the percentage of shoots infested with woolly apple aphid in mid-late summer.

\begin{tabular}{|c|c|c|c|c|c|}
\hline $\begin{array}{l}\text { Treatments } \\
\text { (product per } 100 \text { litres) }\end{array}$ & $\begin{array}{l}\text { No of } \\
\text { plots }\end{array}$ & $\begin{array}{l}\text { Weekly } A \text {. } \\
\text { prior to } \\
\text { treatment }\end{array}$ & $\begin{array}{l}\text { mali catch } \\
\text { post- } \\
\text { treatment }\end{array}$ & & $\begin{array}{l}\text { Percent shoots } \\
\text { infested with } \\
\text { WAA }\end{array}$ \\
\hline \multicolumn{5}{|l|}{ September treatments } & late-January \\
\hline \multicolumn{6}{|l|}{ Hawkes Bay } \\
\hline oil (2 litres) & 3 & - & 1.13 & & $5.3 \mathrm{a}$ \\
\hline oil + buprofezin $(50 g)$ & 3 & - & 0.87 & & $1.8 \mathrm{a}$ \\
\hline oil + chlorpyrifos $(100 \mathrm{ml})$ & 3 & - & & $\mathrm{b}$ & $0.2 \mathrm{a}$ \\
\hline \multicolumn{6}{|l|}{ Nelson } \\
\hline oil + buprofezin $(50 g+50 g)$ & 2 & - & 0.42 & & $1.8 \mathrm{y}$ \\
\hline oil + chlorpyrifos $(100 \mathrm{ml})$ & 2 & - & 0.09 & & $0 \mathrm{y}$ \\
\hline November treatments & & & & & late-January \\
\hline \multicolumn{6}{|l|}{ Hawkes Bay } \\
\hline carbaryl $(100 \mathrm{~g})$ & 1 & 2.7 & 0.3 & $*$ & 62.0 \\
\hline diazinon $(100 \mathrm{~g})$ & 1 & 6.7 & 7.8 & n.s. & 37.0 \\
\hline untreated & 1 & 2.0 & 1.8 & & 31.5 \\
\hline \multicolumn{6}{|l|}{ January treatments } \\
\hline \multicolumn{6}{|l|}{ Hawkes Bay } \\
\hline pirimicarb $(50 g)$ & 2 & 4.0 & 14.6 & n.s. & 8.0 \\
\hline untreated & 1 & 2.5 & 14.0 & & 65.5 \\
\hline
\end{tabular}

${ }^{1}$ Time interval described in methods. Green tip treatments - lower case letters denote difference at $5 \%$ level of significance. Other treatments analysed T-test described in McDonald and Erickson (1994), n.s. = not significant, $*$ = significantly different at 10\% level of significance.

\section{Field Study}

The number of A. malicaught in white sticky traps from chlorpyrifos treated plots was significantly reduced in both districts, although by late January the populations of WAA did not differ between plots (Table 2). This indicates that while A. mali activity was disrupted by chlorpyrifos, this treatment gave season long WAA control in small plots.

Field use of diazinon in November gave results that conflicted with the laboratory bioassay. Diazinon did not reduce the number of $A$. mali caught after treatment and the population of WAA was similar to that in the untreated control two months after treatment, indicating biological control was not disrupted. There was a reduction in the number of $A$. mali caught $(\mathrm{P}=0.07)$ following carbaryl treatment and WAA populations increased to a higher level than in the untreated and diazinon treated plots.

The current IFP threshold for WAA (10\% of shoots infested (Walker et al. 1997)) was exceeded in all three Fuji plots. The carbaryl and diazinon treated plots received pirimicarb, which provided excellent control of WAA, while showing no significant reduction of $A$. mali activity in the four weeks following treatment (Table 2). Pirimicarb provided excellent control of WAA where A. mali was present in field trials (Table 2). We found it had no effect on adultA. mali in the laboratory (Table 1), or in the field (Table 2) and El-Haidari and Georgis (1978) showed no effect on pupae. Pirimicarb has excellent potential as a selective aphicide within IFP programmes.

Implications for Integrated Fruit Production 
The three broad-spectrum insecticides (carbaryl, chlorpyrifos and diazinon) still included in New Zealand IFP guidelines (Anon. 1996) were highly toxic to adult A. mali. This does not mean that they should be excluded from the programme, as field trials indicated that chlorpyrifos plus oil at green-tip or a single application of diazinon in November was not disruptive to WAA populations. However, the potential impact of these pesticides on other beneficial species (e.g. leafroller parasitoids) makes it desirable to seek alternatives that are more universally compatible with biological control. The small plot size in this study probably contributed to $A$. mali immigration, which reduced more serious disruption to biological control. Accordingly growers could 'spot treat' areas that have aphid infestations or only treat "at risk" cultivar blocks rather than treating entire orchards with pesticides that have the potential to disrupt biological control.

By applying pesticides during periods where adult $A$. mali activity is low (mid-Dec to January and during winter), there is a possibility of avoiding adverse effects against this life-stage. Unfortunately timing of carbaryl must coincide with fruit development, as it is primarily used as a fruit thinning agent at petal-fall when adults are active. Since carbaryl has been shown to be disruptive to A. mali in this study, its acceptability in IFP should be questioned as alternative thinning compounds are approaching full regristration (S. Tustin pers. comm.). In the interim growers should avoid the widespread use of carbaryl, restricting its use to where there are no alternative fruit thinning compounds.

\section{ACKNOWLEDGEMENTS}

We would like to thank Roger Wallis for field assistance, Max Suckling for statistical advice, as well as the Foundation for Research, Science and Technology and ENZA New Zealand (International) for financial support.

\section{REFERENCES}

Abbott, W. S., 1925. A method of computing the effectiveness of an insecticide. Econ. Entomol. 18 (2):265-7.

Anon., 1996. New Zealand Integrated Fruit Production - Pipfruit Manual. ENZA New Zealand (International), Hastings.

Batchelor, T.A., Walker, J. T. S., Manktelow, D. W. L., Park, N. M. and Johnson, S. R., 1997. New Zealand integrated fruit production for pipfruit - charting a new course. Proc. 50th N.Z. Plant Prot. Conf:: (this volume).

Croft, B.A., 1982. Arthropod resistance to insecticides: a key to pest control failures and successes on North American apple orchards.Entomol. Exp. et Appl. 31: 88-110.

Haidari, H. S. El- and Georgis, R., 1978. The toxicity of some pesticides to the woolly apple aphid parasite, Aphelinus mali. PANS 24(2): 109-110.

McDonald, L. L. and Erickson, W. P., 1994. Testing for bioequivalence in field studies: has a disturbed site been adequately reclaimed? Pp. 183-198In: Statistics in Ecology and Environmental Monitoring. D.J. Fletcher and B.F.J. Manly (Eds.), University of Otago Press.

Schneider, H., 1958. Untersuchungen über den einflub neuzeitlicher insektizide und fungizide auf die blutlauzehrwespe (Aphelinus mali Hald.). Zeitschrift fuer angewandte Entomologie 58: 173-196.

Shaw, P.W. and Walker, J.T.S., 1996. Biological control of woolly apple aphid by Aphelinus mali in an integrated fruit production programme in Nelson. Proc. 49th N.Z. Plant Prot. Conf:: 59-63.

Walker, J.T.S., Hodson, A.J., Wearing, C.H., Bradley, S.J., Shaw, P.W., Tomkins, A.R., Burnip, G.M., Stiefel, H.E., and Batchelor, T.A., 1997. Integrated fruit production for New Zealand pipfruit: evaluation of pest management in a pilot programme. Proc. 50th N.Z. Plant Prot. Conf:: (this volume). 